\title{
TURISMO, NEOLIBERALISMO E DESENVOLVIMENTO: REFLEXÕES E INTERFACES
}

TOURISM, NEOLIBERALISM AND DEVELOPMENT: REFLECTIONS AND INTERFACES

Juliana Ferreira da Silva', Carla Holz ${ }^{2}$, Bruno Martins Augusto Gomes ${ }^{3}$

RECEBIDO EM: 25/05/2019 | ACEITO EM: 12/03/2020

DOI: $10.5902 / 2317175838276$

\section{RESUMO}

Este trabalho objetiva realizar uma discussão crítica e teórica sobre o turismo e o neoliberalismo, contemplando aspectos do desenvolvimento a serem destacados no debate. Para isso, foi realizada uma revisão teórica em torno dos temas turismo, neoliberalismo e desenvolvimento por meio de pesquisas bibliográficas. A partir da pesquisa foi possível perceber que um dos principais desafios para o desenvolvimento democrático do turismo numa sociedade neoliberal está no grande apelo ao lucro, em detrimento da valorização de aspectos socioculturais. Como principais considerações, foi possível elencar alguns dos desafios que permeiam o turismo numa sociedade neoliberal, visualizar as possibilidades que permitem reavaliar condutas e propor novos olhares para o desenvolvimento democrático do turismo, bem como sugerir abordagens para pesquisas futuras.

Palavras-chave: Turismo; Neoliberalismo; Desenvolvimento.

\footnotetext{
1 Mestranda em Políticas Públicas pela Universidade Federal do Paraná. Possui bacharelado em Turismo pela Universidade Federal do Paraná (2010) e especialização em Gestão Pública e Sociedade com foco em Economia Solidária pela Universidade Federal de Tocantins (2012). Lattes: http://lattes.cnpq.br/3948407308028996 Universidade Federal do Paraná - UFPR. Brasil

2 Mestranda em Turismo pela pela Universidade Federal do Paraná. Possui bacharelado em Letras - Português e Inglês pela Faculdades Integradas Santa Cruz de Curitiba(2017). Graduanda em Turismo pela Universidade Federal do Paraná. Lattes: http://buscatextual.cnpq.br/buscatextual/visualizacv.do?id=K2183336Z6 Universidade Federal do Paraná - UFPR. Brasil

3 Professor do Departamento de Turismo e do Programa de Pós-graduacão em Turismo da Universidade Federal do Paraná (UFPR). Co-líder do grupo de pesquisa Turismo e Sociedade (UFPR) e pesquisador do Núcleo de Estudos em Instituições (UFPR). Coordenador do CELEXTUR - Centro de Estudos do Legislativo, Executivo e o Turismo (UFPR). Atua principalmente com os seguintes temas: turismo, políticas públicas, direito, economia institucional e responsabilidade social. Doutor em Políticas Públicas pela Universidade Federal do Paraná (UFPR). Mestre em Administração pela Universidade Federal de Lavras (UFLA). Bacharel em Turismo pela Universidade Federal de Ouro Preto (UFOP). Lattes: http://buscatextual.cnpq.br/buscatextual/visualizacv.do?id=K4717821E2 Universidade Federal do Paraná - UFPR. Brasil
} 


\begin{abstract}
This study aims to stimulate a critical and theoretical discussion on tourism and neoliberalism, by considering development as an important aspect for the debate. For that, this study engages in bibliographic researches about tourism, neoliberalism and development. Based on this research, it was possible to realize that one of the main challenges for the democratic development of tourism in a neoliberal society is the profit appeal in detriment of the valorization of socio-cultural aspects. It is argued some of the challenges faced by tourism in a neoliberal society, the possibilities that allow reassessment of conduct and propose new perspectives for the democratic development of tourism, as well as to observe approaches for future researches.
\end{abstract}

Keywords: Tourism; Neoliberalism; Development.

\title{
1 Introdução
}

Assim como a concepção de desenvolvimento, a de turismo é comumente atrelada ao viés econômico. Tal compreensão negligencia sua capacidade de expansão de melhorias sociais e de proporcionar sociedades mais democráticas. Assim, o entendimento do turismo como alternativa para o desenvolvimento contempla-o como um fenômeno social que transcende a perspectiva, muitas vezes engessada, que considera a atividade puramente como um processo econômico. O turismo enquanto manifestação social abarca aspectos culturais, políticos e econômicos de interação em uma sociedade produzida a partir do movimento histórico do capitalismo.

Diante disso, é importante contextualizar a atividade no cenário do capitalismo e, mais especificamente, do neoliberalismo, posto que o turismo influencia e sofre influências do sistema de produção no qual está inserido. Todavia, por muito tempo, pouca atenção foi dada aos efeitos desse fato.

Mas quais são os efeitos do neoliberalismo no turismo? Quais são os principais aspectos a serem abordados, nesse contexto, ao se falar em desenvolvimento? O presente artigo objetiva realizar uma discussão crítica e teórica sobre o turismo e o neoliberalismo, contemplando aspectos do desenvolvimento a serem destacados no debate. Para tanto, foram realizadas pesquisas bibliográficas, especialmente em livros e artigos científicos, tendo em vista a relação das três vertentes que compreendem o mote da pesquisa: turismo, neoliberalismo e desenvolvimento.

A primeira seção discute o neoliberalismo por meio de uma abordagem crítica sobre as imbricações deste sistema, e expõe o cenário no sentido de constatar algumas influências no turismo. Nesta seção, também será abordado o desenvolvimento a partir da perspectiva democrática, tendo em vista alguns temas que convergem para uma concepção ampla de desenvolvimento que merece destaque ao considerar o turismo. Por fim, são apresentadas as considerações finais conectando os temas expostos e propondo possibilidades para pesquisas futuras. 
TURISMO, NEOLIBERALISMO E DESENVOLVIMENTO:

REFLEXÕES E INTERFACES

\section{Turismo no contexto do neoliberalismo: uma visão crítica}

Ao tratar de neoliberalismo é importante considerar o fenômeno como um processo histórico em uma sociedade complexa, permeada por incongruências e por conflitos. Nesse sentido, a história das civilizações e das sociedades não é suave e remete a momentos de ruptura, muitas vezes pontos de partida para transformações e remodelações na sociedade.

Para Jan Mosedale (2016), é difícil apontar, com precisão, o momento em que o neoliberalismo emergiu na sociedade. Conquanto as discussões tenham iniciado no final da década de 1930, a ascensão do neoliberalismo ocorreu com a crise financeira dos anos 1970, com a derrocada do keynesianismo. Acontecimentos políticos impulsionaram o processo, como a experiência chilena, com Pinochet, que formou estudantes de Friedman na Universidade de Chicago (também conhecidos como Chicago boys); e os governos de Margaret Thatcher, no Reino Unido, e de Ronald Reagan, nos Estados Unidos, com foco na privatização e na implementação de medidas garantidoras de estabilidade fiscal e de crescimento econômico.

Os movimentos históricos ao longo do século XX são fundamentais para a análise do contexto do qual o Estado faz parte. William Mitchell e Tomas Fazi (2017) abordam a transição keynesiana para a neoliberal impulsionada por crises econômicas ao longo do período. As mudanças e rupturas de um modelo para outro configuram reflexões essenciais.

O keynesianismo emergiu no período pós-Segunda Guerra Mundial com o Acordo de Bretton Woods, que congregou países com a finalidade de construir a nova ordem hegemônica mundial, conforme assevera Barry Eichengreen (2000). A doutrina keynesiana, que recebeu este nome em homenagem ao economista John Maynard Keynes, defende que o Estado possui papel preponderante na organização de um país. Filho e Terra (2011) salientam que a teoria keynesiana levou ao surgimento do conceito de Estado de Bem-Estar Social e possui como fundamentos investimentos na área social, controle da inflação, equilíbrio entre demanda e produção, intervenção estatal na economia e garantia do pleno emprego.

Oliveira (1998) sustenta que o processo de mudança para uma nova sociedade passa pelo Estado porque o fundo público é alvo de disputas. Assim, o Estado pode ser fortalecido e, por meio da via institucional, pode confluir esforços para a conformação de políticas públicas de redistribuição e de políticas públicas afirmativas. A acirrada disputa pelo fundo público, abordado por Oliveira (1998), merece destaque no debate, já que é a ferramenta que pode provocar a mudança que delineia o futuro da sociedade.

Para Belluzzo (1995), a derrocada do modelo keynesiano se deu concomitantemente ao fim do Sistema Bretton Woods. O Acordo deu início a uma era de grande expansão do comércio internacional e a crescente interdependência econômica mundial, porém com o fortalecimento da classe trabalhado- 
ra aliado a crises econômicas do período (mormente a do petróleo, a decorrente da desconfiança mundial acerca do padrão ouro-dólar e a impulsionada pela derrota estadunidense na Guerra do Vietnã) o poder e o lucro crescente do grande capital estavam ameaçados. Para Dathein (2002), "pode-se entender estas mudanças, por hipótese, como o fim do keynesianismo e o início da hegemonia de políticas neoliberais" (DATHEIN, 2002, p. 11). O keynesianismo e o neoliberalismo se expressam no mundo concreto de diversas formas de acordo com a condensação de forças que acontecem dentro e fora dos Estados.

A ideologia neoliberal está ligada a um Estado que coaduna com as lógicas da autorregulação dos mercados, da privatização de empresas estatais, da diminuição dos investimentos sociais, da livre circulação de capitais internacionais, da mitigação da força dos trabalhadores e da propagação de valores como consumismo e liberdades individuais. Mosedale (2016) ressalta que as principais características do neoliberalismo são a privatização de ativos nacionais; a comercialização do setor público; a criação de mercados; a desregulação e a regulação; e o foco na autossuficiência de indivíduos e de comunidades.

O modelo neoliberal, segundo Leme (2010), foi fortemente estimulado pelos governos de Margaret Thatcher, na Inglaterra, e de Ronald Reagan, nos Estados Unidos, que, entre outras medidas, reprimiram as greves e cercearam a atuação dos sindicatos em seus países. Leme (2010) salienta que esse novo contexto acentuou a desigualdade mundial e proporcionou o empoderamento e a maior atuação do grande capital.

Convém destacar que o movimento histórico do capitalismo convergiu para o progresso do neoliberalismo. Para David Harvey (2008), o neoliberalismo pode ser entendido como uma nova fase inserida no sistema capitalista, que segue a sua lógica, que se manifesta de diferentes formas e que possui intensidades variadas. Embasado por teóricos como Milton Friedman e Friedrich Hayek, a ideologia neoliberal propõe liberdades individuais, propriedade privada, iniciativa de empreendedores como chaves para a inovação e para a criação de riquezas. Harvey sustenta que a teoria neoliberal entende que a eliminação da pobreza pode ser melhor garantida por meio dos livres mercados e do livre comércio. Mosedale (2016) argumenta que o neoliberalismo prevê que o bem-estar humano pode ser alcançado com o empreendedorismo individual de liberdade de habilidades, sustentado por uma estrutura institucional calcada nos direitos de propriedade e no livre mercado.

Alicerçado na ideia de liberdades individuais, o neoliberalismo e o capitalismo se desenvolvem quando em sinergia com os Estados, pois aqueles só triunfam quando se identificam com este (BRAUDEL, 1987). O autor acrescenta que o capitalismo e o neoliberalismo não são processos exclusivamente econômicos, uma vez que provocam mudanças em nível cultural, social e político. No turismo, Santos Filho (2005) adverte que o conceito de sustentabilidade (e a busca por um equilíbrio entre esses níveis) omite o interesse predominante que é o econômico. 
O modelo neoliberal possui imbricações, conforme ressalta Harvey (2008). A tendência para a superexploração de bens comuns a todos, a transferência para a iniciativa privada de setores geridos e regulados pelos Estados, a competição como virtude primordial, a diminuição de barreiras ao livre movimento, a homogeneização da sociedade global e a competição internacional vista como salutar por proporcionar maior eficiência e produtividade são algumas delas (HARVEY, 2008).

Coggiola (1996) acrescenta que as políticas neoliberais constituem uma tentativa de descarregar a crise do capitalismo nas costas do trabalhador. Há uma elevação da escolaridade formal ligada a uma polivalência dos novos empregados, exigindo uma dedicação ampliada e ao mesmo tempo um aumento dos subcontratados (terceirizados) e um enfraquecimento das representações sindicais, transformando o trabalhador em uma simples agente produtivo (AZEVEDO, 1997).

Sobre esses aspectos, o turismo se destaca na relação com o neoliberalismo tendo em vista a comum precariedade de seus empregos (como navios de cruzeiro, meios de hospedagem, eventos). Essa condição do trabalhador do turismo é agravada pela fragilidade de sua organização sindical e pelas transformações trazidas pelas tecnologias da informação e comunicação e a economia colaborativa, com os respectivos questionamentos sobre a concorrência, a regulamentação governamental, os direitos do consumidor, a tributação e os direitos do trabalhador. Alves e Moreira (2016) ressaltam ainda que as políticas neoliberais associadas à globalização econômica e à expansão do setor de serviços intensificaram as desigualdades de gênero no mercado de trabalho do turismo.

Para Terenciano, Mucache e Salião (2018), ao discutirem o neoliberalismo e seus impactos nas políticas públicas de turismo e na dinâmica cotidiana da população em Moçambique, manifestam que o neoliberalismo, expressão atual do capitalismo, deturpou o conceito do turismo, reduzindo-o simplesmente ao desenvolvimento econômico. Os autores defendem que a política de turismo em Moçambique possui uma metafísica empresarial e, por conseguinte, deve ser visto como uma questão social que necessita de reflexões no contexto globalizado.

Diante deste cenário, o Estado está imerso em um ambiente de assimetrias. Bob Jessop (1997) assevera que neste contexto há tendências de desnacionalização do Estado, como a perda de seu poder de decisão para instâncias supranacionais, a desestatização do sistema político e a ideia de que governanças são mais importantes. Destarte, vale ressaltar que o papel do Estado é fundamental, não somente como instância reguladora, normatizadora, administradora e organizadora da ordem social, mas também como promotor de mudanças sociais e de desenvolvimento. Como observado por Souza (2019), em oposição ao entendimento neoliberal é importante que as políticas públicas atuem em prol da redução da redução da pobreza, do desemprego, da exclusão social e da violência. 
Diante disso, as atividades como o turismo são também moldadas por este sistema de produção. Mosedale (2016) sustenta que o turismo no contexto do neoliberalismo sofreu modificações tanto positivas quanto negativas, a depender do segmento e do setor em análise. Esse autor defende que a privatização de ativos nacionais, como o transporte, acarretou impactos negativos em muitos setores da atividade turística, porém algumas áreas específicas foram beneficiadas com as privatizações, como o segmento de turismo de saúde, no qual turistas exploram diferenças político-econômicas entre lugares para o seu bem-estar e, portanto, a privatização dos ativos nacionais fomentou as viagens com fins medicinais e de saúde.

A comercialização do setor público, por sua vez, pode ser retratada por meio de medidas adotadas para preservação da biodiversidade (de parques e de áreas naturais, por exemplo), na qual os locais são levados a superar o suporte governamental por meio de inovação de fundos, em um contexto de mercado; a comercialização das áreas protegidas envolve, por conseguinte, a cobrança de taxas para a manutenção dos serviços de proteção (Mosedale, 2016). A criação de mercados é evidenciada por meio da monetarização de esferas da sociedade e de bens não renováveis, uma vez que até mesmo cotas para a degradação do meio ambiente são vendidas em mercados, como os créditos de carbono. A desregulação como estratégia permite a competição, a autorregulação de mercados e a redução da atuação governamental, o que pode atrair mais investimentos - um exemplo claro é a desregulação do setor de tráfego aéreo, que facilitou a entrada de produtos, sem barreiras de trânsito, taxas, quantidades e outras cotas. Já a regulação estruturou as relações entre capital, instituições e sociedade, na qual a arena política do turismo pode ser caótica e calcada em uma variedade de escalas geográficas. O foco na autossuficiência de indivíduos e de comunidades é uma característica do neoliberalismo, ao passo que desconsidera desigualdades estruturais e entende o indivíduo como um ator racional que negocia e empreende em mercados livres (MOSEDALE, 2016).

No Brasil, o transporte aéreo de passageiros deve ser considerado na análise do neoliberalismo no contexto do turismo. As políticas públicas neoliberais voltadas para a abertura de mercado, para a competição nacional e internacional e para privatizações do transporte aéreo marcam o histórico do setor. Como expõem Gomes, Bahl e Teles (2016) no transporte aéreo o Estado deve atuar como regulador e não produtor. Os autores acrescentam que especialmente no Brasil essa atuação do Estado é essencial tendo em vista o interesse social do serviço perante a necessidade de deslocamento em um país continental, além das exigências de qualidade e segurança.

Semelhante a este e relacionado às políticas públicas neoliberais, no Brasil, está o caso da Estação Ecológica de Tamoios, localizada na região sudeste, na Costa Verde Fluminense. A Estação Ecológica é reconhecida como uma Unidade de Conservação de Proteção Integral pela Lei $n^{\circ}$ 9.984/2000, que institui 
o Sistema Nacional de Unidades de Conservação da Natureza. A Estação Ecológica tem como objetivo a preservação da natureza e a realização de pesquisas científicas e, para isso, sua posse e seu domínio são públicos, sendo que áreas particulares são desapropriadas e a visitação pública é proibida, exceto com o objetivo educacional, conforme o Plano de Manejo da unidade. No caso específico de Tamoios, há um debate acerca do aproveitamento da área para fins turísticos. De um lado, os neoliberais acreditam que Tamoios deve deixar de ser uma Estação Ecológica para passar a receber turistas e ter permissão para construções de grande porte, a fim de receber grandes empreendimentos hoteleiros e melhorar a infraestrutura turística do local. De outro lado, os ambientalistas e alguns pesquisadores defendem que acabar com a Estação Ecológica afetaria o turismo justamente porque a motivação dos visitantes está relacionada à preservação da área, que a torna um paraíso ecológico.

Em relação às políticas públicas de turismo no Brasil, Bursztyn salienta o risco de elas serem desenvolvidas sob a égide neoliberal, ou seja, a tendência de priorizar a formação de produtos turísticos voltados para o grande mercado, forçando assim a adequação das condições locais no sentido de alcançar maior eficiência nos serviços prestados com o objetivo de aumentar a lucratividade (BURSZTYN, 2003).

Contudo, é importante destacar que o turismo pode ser uma alternativa para o desenvolvimento. Assim, Maldonado (2009) assevera que o turismo representa um complemento ao progresso econômico e ocupacional e permite potencializar e dinamizar as atividades tradicionais nas comunidades. Por esse motivo, é preciso considerar o turismo como uma atividade capaz de promover o desenvolvimento econômico e social, alicerçado em medidas que garantam práticas democráticas, como a liberdade de participação e a transparência das ações tomadas pelo governo.

Nesse aspecto, Acosta (2016) alerta que o mundo ordenou o desenvolvimento como um imperativo, oferecendo planos, programas, projetos, teorias e manuais como meios para alcançar esse objetivo. Para o autor, esse desenvolvimento culminou, inclusive, numa aceitação do "vale-tudo", regra em que tudo é tolerado em nome do progresso, desde a aceitação da devastação ambiental e social até a negação das raízes históricas e culturais. Esse alerta é fundamental para definir de maneira consciente e crítica quais ações de promoção do turismo serão aplicadas e, ainda, se essas ações de fato contribuirão para o desenvolvimento social e econômico das comunidades em que serão implementadas.

Há uma grande diversidade de prismas de análise para estratégias de desenvolvimento. Stiglitz (2006) enfatiza que muito embora Consenso de Washington defenda como estratégias o Estado mínimo, a ênfase à privatização, à liberalização do mercado e à desregulação do setor, na prática esta tática deu pouca ênfase à igualdade. Assim, o autor defende pilares para o desenvolvimento ou alternativas para um desenvolvimento mais democrático. 
Nesse sentido, é necessário aliar as esferas: mercado, governo, indivíduos e comunidades, a fim de compartilhar o crescimento econômico, de promover a qualidade de vida da população, de expandir as liberdades individuais e de fortalecer cada vez mais a democracia.

Sen (2000) afirma que o desenvolvimento requer a retirada das principais fontes de privação da liberdade, como a pobreza, a carência de oportunidades e a negligência dos serviços públicos, e a liberdade é elemento fundamental não apenas para o desenvolvimento, como também para o exercício democrático. Por esse motivo, antes de propor medidas de desenvolvimento por meio do turismo, é necessário observar se os aspectos básicos que garantem a participação da comunidade local estão sendo respeitados.

Segundo Freire (2011), é a partir da liberdade que o sujeito se torna apto para pensar e dialogar de maneira independente, responsável e, preferencialmente, ética, pois a liberdade implica escolhas que, somente quando praticadas com responsabilidade, serão éticas. Sobre a importância da liberdade no contexto de interação social, Comparato afirma que "a verdadeira liberdade não é uma situação de isolamento, mas, bem ao contrário, o inter-relacionamento de pessoas ou povos, que se reconhecem reciprocamente dependentes, em situação de igualdade de direitos e deveres" (COMPARATO, 2006, p. 537).

A respeito desse diálogo entre liberdade e democracia, Sen (2000) alerta que a violação da liberdade resulta diretamente na negação de outras liberdades - como as políticas e as civis, e essa se concretiza a partir de regimes autoritários que impõem restrições à liberdade de participação da vida social, política e econômica da comunidade. Por esse motivo, o autor afirma que a expansão das liberdades humanas é tanto o principal fim como o principal meio de desenvolvimento. $O$ autor lista as facilidades econômicas, as liberdades políticas, as oportunidades sociais, as garantias de transparência e a segurança protetora como papéis instrumentais da liberdade. Apenas num contexto em que são garantidos os direitos fundamentais, o indivíduo encontra oportunidade de contribuir para o desenvolvimento da comunidade a que pertence.

Para que haja o desenvolvimento econômico e social do turismo é preciso garantir um ambiente coerentemente democrático e com liberdade de participação da comunidade local. Em pesquisa realizada em oito comunidades na costa leste do Estado do Ceará, Salles e Sales (2012) observaram o desenvolvimento do turismo pautado na ética e na solidariedade. As autoras informam que esses vilarejos firmaram redes colaborativas estabelecidas a partir de vínculos sociais espontâneos, e que a gestão coletiva das atividades valorizava o trabalho humano, a cooperação e a participação dos membros da comunidade. Nesse sentido, as pesquisadoras alertam que a comunicação e a interatividade intensa e verdadeira são elementos fundamentais para que os processos ocorram de maneira democrática e transparente.

Como exposto por Sen (2000), apenas com oportunidades sociais adequadas os indivíduos podem efetivamente moldar seu próprio destino e aju- 
TURISMO, NEOLIBERALISMO E DESENVOLVIMENTO:

REFLEXÕES E INTERFACES

dar uns aos outros. Apenas dessa forma o turismo pode ser considerado uma atividade capaz de promover a participação e o desenvolvimento social e econômico de comunidades que são beneficiadas pela atividade. Mas como alertam Martoni e Varajão (2009), a participação da sociedade no turismo como forma de contrabalancear os interesses de grupos dominantes no desenvolvimento por meio do turismo é precedida pelo descortinar das aparências das políticas neoliberais.

\section{Considerações finais}

O turismo, enquanto atividade capaz de promover o desenvolvimento econômico e social, não pode ser concebido sem a visão crítica dos atores envolvidos em sua dinâmica. O presente trabalho buscou realizar uma discussão crítica e teórica sobre o turismo e o neoliberalismo, contemplando aspectos do desenvolvimento abordados no debate.

A pesquisa realizada mostrou os principais desafios para o desenvolvimento democrático da atividade turística numa sociedade neoliberal. É importante destacar que a contribuição econômica gerada a partir do turismo beneficia as comunidades envolvidas, porém é necessário também reafirmar o posicionamento consciente dos grupos responsáveis pela formulação e implantação de propostas de desenvolvimento da atividade. Para isso, o artigo assumiu principalmente as constatações de Jan Mosedale, que aborda o tema de turismo e neoliberalismo no sentido de ilustrar, avaliar e explicar os efeitos das variáveis do neoliberalismo no turismo por meio de exemplos estruturados.

Como apresentado neste estudo, o turismo é capaz de contribuir para o desenvolvimento econômico e social das comunidades, na valorização da cultura local e na geração de renda das comunidades beneficiadas pela atividade. Inseridos em um contexto neoliberal, os benefícios econômicos gerados a partir do turismo devem ser apontados como um aspecto positivo, ao mesmo tempo que o desenvolvimento social e a liberdade de participação da comunidade local devem ser assegurados. Nesse cenário, um dos principais desafios para o desenvolvimento democrático do turismo em uma sociedade neoliberal é o forte apelo lucrativo em detrimento dos valores sociais e culturais.

Dessa forma, o desenvolvimento democrático do turismo aparece como uma possibilidade para reavaliar condutas e propor novos olhares para a atividade. Elencar os principais desafios e, a partir deles, propor uma reflexão crítica, é uma forma de atribuir ao turismo o seu local merecido, ou seja, o de fenômeno social promotor de um direito social ao lazer e que ao mesmo tempo contribui para o desenvolvimento cultural, social e econômico de um Estado.

O presente estudo não teve a pretensão de esgotar a pauta apresentada, já que apenas alguns autores que se dedicam à temática foram aqui aludidos. Assim, pesquisas futuras podem se dedicar ao assunto proposto neste 
artigo a partir da abordagem de outros teóricos. Convém destacar também que, para além desta pesquisa, recomenda-se a análise de outras variáveis a serem investigadas. O papel do Estado no turismo, as políticas públicas e sua relação com o desenvolvimento, as instituições de participação democrática que podem contribuir para o turismo e a ética e a responsabilidade social frente ao neoliberalismo são algumas delas.

A partir dessa análise, observando experiências na esfera internacional, é possível formular lições sobre a ação pública no turismo frente ao neoliberalismo que podem contribuir tanto para a formulação de projetos de lei, quanto para a elaboração de políticas públicas na área pesquisa. Em termos acadêmicos, permite a expansão dos estudos sobre a interação entre empresários e setor público no turismo sob a ótica do neoliberalismo e do desenvolvimento.

\section{REFERÊNCIAS}

ACOSTA, A. O Bem Viver. São Paulo, Autonomia Literária, 2016.

ALVES, K.S., \& MOREIRA, M.I.C. Trabalho em turismo e relações de gênero. In: ALVES, K.S. Turismo, trabalho e gênero: uma abordagem interdisciplinar. Ouro Preto: Rona Editora, 2016.

AZEVEDO, J.S.G. Programas de qualidade alguns impactos sobre o trabalho em pequenas e microempresas da Bahia. In: CARLEIAL, L.; VALLE, R. (Orgs.) Reestruturação Produtiva e Mercado de Trabalho no Brasil. São Paulo: Hucitec/ABET, 1997.

BELLUZZO, L. G. M. O declínio de Bretton Woods e a emergência dos mercados "globalizados". Economia e Sociedade, n. 4, IE-Unicamp, 1995.

BRAUDEL, F. A Dinâmica do Capitalismo. Rio de Janeiro: Ed. Rocco, 1987.

BURSZTYN, I. A influência do ideário neoliberal na formulação de políticas públicas de turismo no Brasil. Caderno Virtual de Turismo, v. 3, n. 4, p. 7-12, 2003.

COGGIOLA, O. Neoliberalismo Futuro do Capitalismo. In: KATZ, C. e COGGIOLA, O. Neoliberalismo ou crise do capital? São Paulo: Xamã, 1996.

COMPARATO, F. K. Ética. São Paulo: Companhia das Letras, 2006.

DATHEIN, R. De Bretton Woods à Globalização Financeira: Evolução, crise e perspectivas do Sistema Monetário Internacional. Anais do VII Encontro Nacional de Economia Política. Curitiba, 2002.

EICHENGREEN, B. A globalização do capital: uma história do sistema monetário internacional. São Paulo: Editora $34,2000$.

FILHO, F. F., \& TERRA, F. As disfunções do capitalismo na visão de Keynes e suas proposições reformistas. Revista de Economia Contemporânea, v. 15, n. 2, p. 271-295, 2011.

FREIRE, P. Pedagogia da autonomia: saberes necessários à prática educativa. São Paulo: Paz e Terra, 2011.

GOMES, B. M. A., BAHL, M., \& TELES, M. A. Estado, Desenvolvimento e Turismo: um enfoque no transporte aéreo de passageiros. In: ANJOS, F. A.; ANGELI, N. P. Turismo e Desenvolvimento Econômico. Itajaí, Univali, 2016.

HARVEY, D. O neoliberalismo: história e implicações. São Paulo: Ed. Loyola, 2008.

JESSOP, B. Capitalism and its future: remarks on regulation, government, and governance. Review of International Political Economy, n.4, v.3, p.435-455, 1997.

LEME, A. A. Neoliberalismo, globalização e reformas do Estado: Reflexões acerca da temática. Barbarói, Santa Cruz do Sul, n. 32, p.114-138, 2010 
TURISMO, NEOLIBERALISMO E DESENVOLVIMENTO:

REFLEXÕES E INTERFACES

MALDONADO, C. O turismo rural comunitário na América Latina: gêneses, características e políticas. In: BARTHOLO, R.; SANSOLO, D. G.; BURSZTYN, I. (Org). Turismo de Base Comunitária: diversidade de olhares e experiências brasileiras. Ministério do Turismo. Letra e Imagem, 2009. p. 25-44.

MARTONI, R. M, \& VARAJÃO, G. F. D. C. Caminhos Opostos: turismo nas Estradas Reais de Minas Gerais. Rio de Janeiro: Libre Expressão, 2009.

MITCHELL, W., \& FAZI, T. Reclaiming the State: A progressive vision of sovereignty for a post-neoliberal world. Pluto Press, 2017.

MOSEDALE, J. Neoliberalism and the political economy of tourism: projects, discourses and practices. In: MOSEDALE, J. Neoliberalism and the Political Economy of Tourism. Oxon: Routledge, 2016.

OLIVEIRA, F. de. Os Direitos do Antivalor. Petrópolis: Vozes, 1998.

SALLES, M. R. R., \& SALES, G. A. F. O sistema da dádiva nas relações comunitárias e a constituição de alianças pelo trabalho tradicional. Revista de Cultura e Turismo, n. 2, p. 20-42, 2012.

SANTOS FILHO, J. Ontologia do Turismo. Caxias do Sul: Educs, 2005.

SEN, A. Desenvolvimento como liberdade. São Paulo: Companhia das Letras, 2000.

SOUZA, S. R. de. Turismo e educação: implicações para a formação do turismólogo. In: GOMES, B.M.A., \& BAHL, M. (Org.) Turismo e Sociedade: aspectos teóricos. São Paulo: All Print, 2019.

STIGLITZ, J. E. Making globalization work. New York: W. W. Norton \& Company, 2006.

TERENCIANO, F., MUCACHE, C. R., \& SALIÃO, A. Neoliberalismo e Percepções da Importância do Turismo em Moçambique: uma discussão crítica e prática. Revista Turismo e Sociedade, v. 11, n. 1, p. 147-168, 2018. 